\title{
Women and Venous Disease of the Lower Limbs
}

\author{
Musil D* \\ Department of Internal Medicine I-Cardiology, Teaching Hospital, Olomouc, Czech Republic \\ *Corresponding author: Musil D, Department of Internal Medicine I-Cardiology, Teaching Hospital, Olomouc, Czech Republic
}

Received: March 02, 2021; Accepted: March 08, 2021; Published: March 22, 2021

The most common occasions for phlebological examination in women are edema of the lower limbs and varicose veins. These are closely related. One study investigating the cause of leg edema of unknown origin found lymphatic insufficiency, Chronic Venous Disease (CVD) or both in $70 \%$ of patients [1]. There is also a close relationship between the two diseases. Long lasting CVD causes tissue damage, lymphatic dysfunction and phlebolymphedema. On the other hand, progressive lymphedema causes leg imobility, failure of the calf-muscle venous pump and venostasis.

CVD is one of the most frequent disorders in European countries. The incidence of this condition increases with age and is higher among women than among men but the difference in prevalence between the sexes is small. The cross-sectional Edinburgh Vein Study found that telangiectases and reticular veins were each present in approximately $80 \%$ of men and $85 \%$ of women [2]. Risk factors for CVD include female sex and pregnancy in addition to heredity, age, obesity, prolonged standing and greater height [3]. For women, therefore, we encounter an accumulation of risk factors even at a young age (heredity, pregnancy, obesity, prolonged standing).

Very often, CVD in women first appears or worsens with pregnancy. The role of obesity is controversial and the evidence on Body Mass Index (BMI) for CVD is inconclusive. Some studies have found different risks for women and for men, a positive association of increased BMI with varicose veins in women [4,5] or only in postmenopausal women [6] but not in men. Other authors suggest obesity as a risk factor in women, but it appears to be an aggravating circumstance rather then a primary cause [7]. According to some studies the frequency of both, visible and functional venous disease, increases with BMI [8]. We found in women a positive correlation between increased BMI and prevalence of venous reflux and between increased BMI and clinical severity/grade of CVD, according to the CEAP classification. Obese women had clinically more severe venous disease [9].

The high prevalence of varicose veins and the chronicity of leg signs and symptoms are the reason for frequent visits of patients in outpatient clinics. In women with an uncomplicated and asymptomatic clinical pattern it is mainly cosmetic concerns. But clinical features of CVD such as pain, swelling, aching, heaviness, cramps, itching, tingling, and restless legs may increase health concerns and many patients are anxious about „circulation problems“. In these cases, initial treatment should be conservative, starting with compression stockings and venoactive drugs. The optimal treatment for telangiectasias and reticular veins is sclerotherapy and for varices and recurrent varicose veins, surgery or endovascular treatment (radiofrequency occlusion and endovenous laser treatment), if the patient agrees and understands all the risks.

Advanced CVD is refereed to as Chronic Venous Insufficiency (CVI) and characterised by skin changes (pigmentation, venous eczema, lipodermatosclerosis, atrophie blanche, leg ulcer). Women seem to develop venous leg ulcers, the most severe manifestation of CVI, more often than men [10]. In obese older women (between 60 and 80 years of age) with CVD, venous ulcers can be a major health problem because of long duration (median nine months) and a considerable impact on health care resources [3]. This condition is usually painful and affects the quality of life. Since the venous ulcer is a chronic condition characterized by slow repair and the tendency to recur, the goal of therapy is not only healing, but also the prevention of recurrence. Compression therapy is able to treat and prevent the ulcer's recurrence. Surgery does not reduce healing time, but it does reduce the incidence of relapses.

A very common condition associated with CVD is superficial vein thrombosis (SVT). In the Calisto trial, for example, almost $90 \%$ of patients with acute, symptomatic SVT suffered from varicose veins [11]. Our study revealed that the risk of SVT in primary CVD was associated with female gender and in both genders to the same extent, age-related [12].

Varicose veins are also referred to as independent and important risk factors for VTE. According to our observation, the risk of VTE associated with varicose veins very significantly rises in the elderly. A family history of VTE, smoking and estrogen hormone therapy in patients with CVD were not revealed as significant risk factors with one exception: smoking increased the risk in obese patients. In women with CVD, the combination of intrinsic and extrinsic factors (BMI, smoking, oral contraceptives/hormone replacement therapy) did not increase the risk of VTE [13].

\section{References}

1. Suehiro K, Furutani A, Morikage N, Yamashita O,Yoshimura K, et al. (2010) Routine diagnostic venous ultrasound and las for leg edema of unknown cause. Ann Vasc Dis 3: 222-227. [crossref]

2. Evans CJ, Fowkes FGR, Ruckley CV, Lee AJ (1999) Prevalence of varicose veins and chronic venous insufficiency in men and women in the general population: Edinburgh Vein Study. J Epidemiol Community Health 53: 149-153. [crossref] 
3. Bergan JJ, Schmid-Schönbein GW, Coleridge Smit, Nicolaides AN, Boisseau MR, et al. (2006) Chronic venous disease. N Engl J Med 355: 488-48.

4. Brand FN, Dannenberg AL, Abbott RD, Kannel WB (1988) The epidemiology of varicose veins: the Framingham Study. Am J Prev Med 4: 96-101. [crossref]

5. Rabe E, Pannier-Fischer F, Bromen K (2003) Bonner Venenstudie der Deutschen Gesellschaft für Phlebologie - epidemiologische Untersuchung zur Frage der Häufigkeit und Ausprägung von chronischen Venenkrankheiten in der städtischen und ländlichen Wohnbevölkerung. Phlebologie 32: 1-14.

6. Iannuzzi A, Panico S, Ciardullo AV, Bellati C, Cioffi V, et al. (2002) Varicose veins of the lower limbs and venous capacitance in postmenopausal women: Relationship with obesity. J Vasc Surg 36: 965-968. [crossref]

7. Robertson L, Evans CJ, Fowkers FG (2008) Epidemiology of chronic venous disease. Phlebology 23: 103-111. [crossref]
8. Chiesa R, Marone EM, Limoni C, Volonté M, Petrini O (2007) Chronic venous disorders: correlation between visible signs, symptoms, and presence of functional disease. J Vasc Surg 46: 322-330. [crossref]

9. Musil D, Kaletová M, Herman J (2011) Age, body mass index and severity of primary chronic venous disease. Biomed Pap Med Fac Univ Palacky Olomouc Czech Repub 155: 253-258. [crossref]

10. De Araujo T, Valencia I, Federman DG, Kirsner RS (2003) Managing the patient with venous ulcers. Ann Int Med 138: 326-334. [crossref]

11. Decousus H, Prandoni P, Mismetti P (2010) Calisto Study Group: Fondaparinuxfor the treatment of superficial-vein thrombosis in the legs. N Eng J Med 363: 1222-1232.

12. Musil D, Kaletová M, Herman J (2016) Risk factors for superficial vein thrombosis in patients with primary chronic venous disease. Vasa 45: 63-66. [crossref]

13. Musil D, Kaletová M, Herman J (2017) Venous thromboembolism - prevalence and risk factors in chronic venous disease patients. Phlebology 32: 135-140. [crossref]

\section{Citation:}

Musil D (2021) Women and Venous Disease of the Lower Limbs. ARCH Women Health Care Volume 4(2): 1-2. 